\title{
Environmental interventions and the pattern of geohelminth infections in Salvador, Brazil
}

\author{
L. R. S. MORAES and S. CAIRNCROSS* \\ Escola Politécnica, Universidade Federal da Bahia, Rua Aristides Novis 2, Federação, 40210-630, Salvador, BA, Brazil
}

(Received 28 November 2003; revised 9 Fanuary and 12 Fanuary 2004; accepted 12 Fanuary 2004)

\begin{abstract}
SUMMARY
This paper reports a longitudinal study, conducted in 1989/90, of 1893 children aged 5 to 14 years in 9 poor urban areas of the city of Salvador (population 2.44 million), capital of Bahia State in northeast Brazil. Stool examinations were performed to measure nematode infection and reinfection 9 months after treatment, and an extensive questionnaire was applied to collect information on each child and on the conditions of the household. Comparison of areas with different levels of infrastructure showed the following trends as the level of community sanitation improved: clustering of cases by household became more significant, predisposition of individuals to reinfection and to heavy infection became more marked, and infections with different species were increasingly aggregated in the same individuals. These results suggest that sewerage and drainage can significantly reduce transmission of intestinal nematode infections in the public domain, but that other measures are required to control transmission within the household.
\end{abstract}

Key words: Ascaris lumbricoides, Trichuris trichiura, hookworm, longitudinal study, reinfection, predisposition, household clustering, sanitation, intervention.

\section{INTRODUCTION}

Much of the literature on the dynamics of infection with intestinal nematodes has tended to consider the host's environment as given, and discussed parameters such as worm aggregation and the predisposition of hosts to reinfection, and to intense reinfection, as if they were intrinsic characteristics of the parasite (Anderson, 1986).

Most authors are careful to state that worm aggregation and predisposition may be the consequence of differences either in host susceptibility or in exposure. However, while chemotherapy and vaccines are in the minds of many (Anderson \& Medley, 1985; Bundy, Chan \& Guyatt, 1995), the idea of altering exposure by environmental or behavioural changes is rarely mentioned in this connection (Kloetzel, 1990). The effect of different environments on transmission dynamics has rarely been studied, with few exceptions (Bundy \& Cooper, 1988).

The distinction is more than academic. If predisposition has its roots in the differential susceptibility of individuals to infection, it indicates that some individuals at least can resist infection, and that studying the mechanism of their resistance could lead to effective preventive measures. If, on the other hand, predisposition to reinfection depends on differential exposure, it suggests an alternative path to a

* Corresponding author: London School of Hygiene and Tropical Medicine, Keppel Street, London WC1E 7HT, UK. Tel: +44(0) 207927 2211. Fax: +44(0) 207636 7843. E-mail: Sandy.Cairncross@1shtm.ac.uk very different type of preventive measure, based on environmental or behavioural change.

We have recently shown how improved urban drainage and sewerage in poor areas of the city of Salvador was associated with a lower incidence of diarrhoea (Moraes et al. 2003) and prevalence of intestinal helminths (Moraes, Cancio \& Cairncross, 2004). Changes in the pattern of risk factors were suggestive of a reduction in transmission in the public domain, relative to domestic transmission (Cairncross et al. 1996). In this paper we report how improved environmental sanitation was also associated with other differences in the pattern of infection and reinfection with Ascaris lumbricoides, Trichuris trichuria and hookworms, particularly aggregation by household and predisposition to reinfection.

\section{MATERIALS AND METHODS}

\section{Study area and population}

The study area included 9 low-income areas in Salvador. Three of these had no sanitary infrastructure (Study Group 1), 3 had benefited from a surface water drainage system in the early 1980s (Group 2) and 3 more had received drainage and also sewerage in the middle 1980s (Group 3). The 3 communities in each study group were chosen at random from the full list of such neighbourhoods $(6,17$ and 11 respectively) with each level of infrastructure in the Camurujipe valley. 
Details of the selection and characteristics of the study population of 1893 children aged 5 to 14 years, of the sanitation interventions implemented in 6 of the 9 study areas, and of the collection and examination of stool samples, have been described elsewhere (Moraes et al. 2003, 2004). The hookworm species Necator americanus and Ancylostoma duodenale were not distinguished although $N$. americanus is predominant in Salvador (Faria, 1972).

The first stool examination was performed on 210 children in each neighourhood. Free treatment ( $200 \mathrm{mg}$ of mebendazole daily for 3 days) was then offered, and accepted by all those examined. Their parents and families were not treated. To ensure that all children took the drug correctly, the field worker asked the mother and the child separately about the treatment and matched their responses. Fifteen days after treatment, a second stool sample was taken from $5 \%$ of these children to check the efficacy of the drug.

Nine months after treatment, stool samples were again collected from all study children, and free treatment was again offered to all those children examined. During the interval, anthelmintics were taken by only a few families and these were excluded from the analysis.

The field was monitored throughout the study period as part of a parallel longitudinal study of diarrhoea. No new physical intervention took place in any of the study neighbourhoods, nor were substantial community-wide changes observed in the households studied that could contribute to alter their health status.

Ethical approval for the study was given by the Department of Health of the State of Bahia, which collaborated in the research. Informed consent was sought at community and at household level. After each round of stool examinations, the results were offered in confidence to the children's parents, assuring complete confidentiality. At the conclusion of the study, further meetings were held to present the results, and a detailed report given to each resident's association so that they could use the findings to lobby the City Administration for better sanitation.

\section{Data handling and analysis}

Data analysis was performed using SPSS/PC+ version 4.0.1. Additional quality control checks were performed before and after data entry. The statistical techniques used included: Chi-squared tests for general associations and for trends in proportion, and Student's $t$-tests and one-way analysis of variance for comparing group means. Because the distribution of egg counts was highly skewed, the average intensity was calculated as the geometric mean of eggs per gram (epg) for those infected. In order to avoid comparisons with very small numbers of cases, 'heavy' infection was defined as having an egg count
Table 1. Distribution of children aged 5-14 years by age, sex and study group: Salvador, Brazil, 1989

\begin{tabular}{lcll}
\hline \hline & $\begin{array}{l}\text { Group 1 } \\
\text { Control } \\
(n=631)\end{array}$ & $\begin{array}{l}\text { Group 2 } \\
\text { Drains } \\
(n=631)\end{array}$ & $\begin{array}{l}\text { Group 3 } \\
\text { Sewers } \\
(n=631)\end{array}$ \\
\hline Chiriable & & & \\
5-6 years & 157 & 157 & 180 \\
7-8 years & 171 & 158 & 141 \\
9-10 years & 126 & 122 & 124 \\
11-12 years & 111 & 106 & 112 \\
13-14 years & 66 & 88 & 74 \\
Mean in years & $8 \cdot 86$ & $9 \cdot 03$ & $8 \cdot 90$ \\
(s.D.) & $(2 \cdot 79)$ & $(2 \cdot 79)$ & $(2 \cdot 71)$ \\
Child's sex & 319 & 350 & 318 \\
Male & 312 & 281 & 313 \\
Female & $66 \cdot 4$ & $47 \cdot 1$ & $38 \cdot 0$ \\
Prevalence of infection $(\%)$ & $71 \cdot 8$ & $68 \cdot 3$ \\
Ascaris lumbricoides & $87 \cdot 8$ & $8 \cdot 6$ & $9 \cdot 4$ \\
Trichuris trichiura & $25 \cdot 2$ & & \\
Hookworm* & & & \\
\hline \hline
\end{tabular}

* Necator americanus or Ancylostoma duodenale.

in the top $20 \%$ of the range (Forrester et al. 1988) for each nematode and study group.

\section{RESULTS}

\section{Study population}

A total of 1928 children aged between 5 and 14 years were found in 795 households of the total of 1005 households surveyed in the 9 study neighbourhoods. In each of Groups 1 and 2 a sample of 631 children was taken from 670 and 657 children surveyed, respectively. The excluded children were those nearest to the boundaries of the age range studied. In Group 3 , where 601 children aged 5 to 14 years were found in the households surveyed, 30 additional children were selected to complete the sample size from the same households but aged 4 years and 15 years. For the purposes of the study they were treated as if aged 5 and 14 years, respectively. The total sample size was thus 1893 children.

The distribution of the children with regard to age and sex is presented in Table 1. In all 3 study groups there were more children in the younger than the older age groups. No significant differences were found between the study groups regarding the age and sex distributions. Also shown are the initial prevalences of infection with each helminth (Moraes et al. 2004).

The households that participated in the nematode study presented similar characteristics to the total of households surveyed (Moraes et al. 2003). No significant differences were found between the study groups in access to electricity, number of bedrooms, household size, religion, animals in the house, type of water supply, or household heads' or mothers' occupations. 
Table 2. Household clustering of cases of nematode infection by study group: Salvador, Brazil, 1989

\begin{tabular}{|c|c|c|c|c|c|c|}
\hline & \multicolumn{6}{|c|}{ No. of households with } \\
\hline & 0 cases & 1 case & 2 cases & 3 cases & 4 cases & $5+$ cases \\
\hline \multicolumn{7}{|c|}{ a. Ascaris lumbricoides } \\
\hline \multicolumn{7}{|c|}{ Group $1^{\text {a }}\left(419\right.$ cases $;$ N.S. $\left.{ }^{b}\right)$} \\
\hline Expected & $36 \cdot 7$ & $99 \cdot 3$ & $66 \cdot 1$ & $33 \cdot 9$ & $14 \cdot 3$ & $5 \cdot 7$ \\
\hline Observed & 60 & 76 & 58 & 33 & 20 & 9 \\
\hline \multicolumn{7}{|c|}{ Group $2(297$ cases; $* * *)$} \\
\hline Expected & $80 \cdot 7$ & $114 \cdot 0$ & $53 \cdot 0$ & $17 \cdot 7$ & $5 \cdot 6^{\mathrm{c}}$ & \\
\hline Observed & 116 & 71 & 53 & 16 & 15 & \\
\hline \multicolumn{7}{|c|}{ Group $3(240$ cases; $* *)$} \\
\hline Expected & $102 \cdot 4$ & $109 \cdot 3$ & $42 \cdot 0$ & $11 \cdot 4$ & $2 \cdot 9$ & \\
\hline Observed & 133 & 76 & 36 & 10 & 13 & \\
\hline \multicolumn{7}{|c|}{ b. Trichuris trichiura } \\
\hline \multicolumn{7}{|c|}{ Group 1 (554 cases; N.S.) } \\
\hline Expected & $28 \cdot 3$ & $69 \cdot 3$ & $71 \cdot 5$ & $44 \cdot 9$ & $25 \cdot 9$ & $16 \cdot 0$ \\
\hline Observed & 25 & 82 & 54 & 45 & 28 & 22 \\
\hline \multicolumn{7}{|c|}{ Group 2 (453 cases; N.S.) } \\
\hline Expected & $33 \cdot 1$ & $107 \cdot 8$ & $72 \cdot 6$ & $37 \cdot 5$ & $13 \cdot 6$ & $6 \cdot 3$ \\
\hline Observed & 52 & 94 & 58 & 42 & 15 & 10 \\
\hline \multicolumn{7}{|c|}{ Group 3 (431 cases; N.S.) } \\
\hline Expected & $37 \cdot 1$ & $107 \cdot 5$ & $72 \cdot 1$ & $32 \cdot 8$ & $13 \cdot 1$ & $5 \cdot 3$ \\
\hline Observed & 59 & 94 & 54 & 34 & 15 & 12 \\
\hline \multicolumn{7}{|l|}{ c. Hookworm } \\
\hline \multicolumn{7}{|c|}{ Group 1 (159 cases ; N.S.) } \\
\hline Expected & $135 \cdot 9$ & $89 \cdot 7$ & $24 \cdot 7$ & $5 \cdot 7$ & & \\
\hline Observed & 153 & 70 & 19 & 14 & & \\
\hline \multicolumn{7}{|c|}{ Group $2(54$ cases; $*)$} \\
\hline Expected & $221 \cdot 5$ & $45 \cdot 2$ & $4 \cdot 3^{\mathrm{c}}$ & & & \\
\hline Observed & 233 & 27 & 11 & & & \\
\hline \multicolumn{7}{|c|}{ Group $3(59$ cases; $*)$} \\
\hline Expected & $214 \cdot 5$ & $48 \cdot 4$ & $5 \cdot 1$ & & & \\
\hline Observed & 224 & 32 & 12 & & & \\
\hline
\end{tabular}

a Group 1-no intervention; Group 2-drainage; Group 3-drainage and sewerage.

b Significance (Chi-squared test): N.S., not significant at $5 \%$ level; $* P<0 \cdot 05$; ** $P<0 \cdot 01 ;$ *** $P<0 \cdot 001$.

c Last cell of each row is for number of cases shown or greater.

\section{Efficacy of treatment}

Fifteen days after treatment a second stool sample was taken randomly from $5 \%$ of the infected children and examined to assess the efficacy of cure. Judged by the absence of nematode eggs in a child's stool after treatment, $89 \%$ of the infected children were then free of $A$. lumbricoides, $93 \%$ were free of hookworm and $69 \%$ were free of $T$. trichiura. No significant differences in efficacy of cure were found between the 3 study groups. Moreover, the egg counts in the few children found to be still infected were very low (the reduction in average intensity for Ascaris was more than $98 \%$, for Trichuris over $97 \%$ and for hookworm more than $95 \%$ ).

\section{Household clustering of infection}

Using the results of the first round of stool examinations, frequency tables (not shown) were constructed for each nematode, and for each study group, indicating the number of households found to have 1,2, 3 or more infected children, by the number of children examined in the household. The expected numbers, for the households with each number of children examined, were calculated from the binomial distribution. The observed and expected frequencies (combining all households) were compared using the Chi-squared significance test, and the overall results are presented in Table 2.

There was a tendency for more households to occur with no infected children, or with more than 3, 2 or 1 infected with Ascaris, Trichuris and hookworm respectively, than would be expected if infected children were randomly distributed. Significant household clustering was observed for $A$. lumbricoides $(P<0 \cdot 01)$ and hookworm $(P<0.05)$ in study Groups 2 and 3 with environmental improvements, but it was not significant in Group 1, the nonintervention group, for any of the nematode species. 


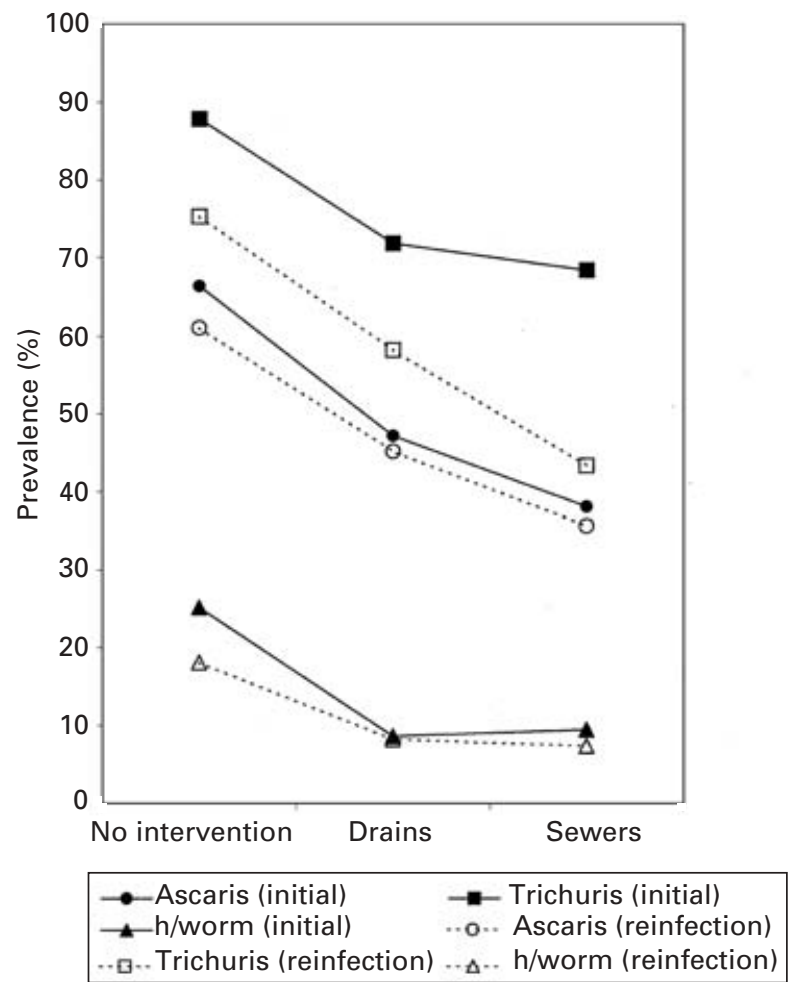

Fig. 1. Intestinal helminth prevalences, initially and after reinfection over 9 months, by sanitation group : Salvador, Brazil, 1989/90.

The appearance of significant household clustering in the 2 study groups with sanitation interventions occurred in spite of the smaller numbers of infected children in those groups. Other things being equal, the smaller numbers would be expected to make any trend less likely to be statistically significant. Indeed the worm species for which this clustering is not significant, Trichuris, is the one for which the prevalence of infection is not much lower in the intervention groups.

\section{Reinfection after chemotherapy}

Of the initial 1893 children, 138 were lost to the study as they could not be examined 9 months after treatment; this loss of $7 \cdot 3 \%$ varied between study groups from $5 \cdot 4 \%$ to $8 \cdot 7 \%$. All these losses were due to the child's family moving away. Those children treated by their parents with anthelminthic drugs between the two examinations $(5 \cdot 4 \%)$ were also excluded, resulting in a total loss during the study period of 241 children, or $12 \cdot 7 \%(10 \cdot 9-14 \cdot 6 \%)$.

Figs 1 and 2 show the prevalence and the geometric mean intensity of infection with Ascaris, Trichuris and hookworm in each study group before and 9 months after treatment. The prevalence and intensity reached by Ascaris and hookworm after 9 months were similar to those before treatment. After reinfection, the relative intensities of Ascaris and Trichuris infections in the 3 study groups were similar to those before treatment, but for hookworm

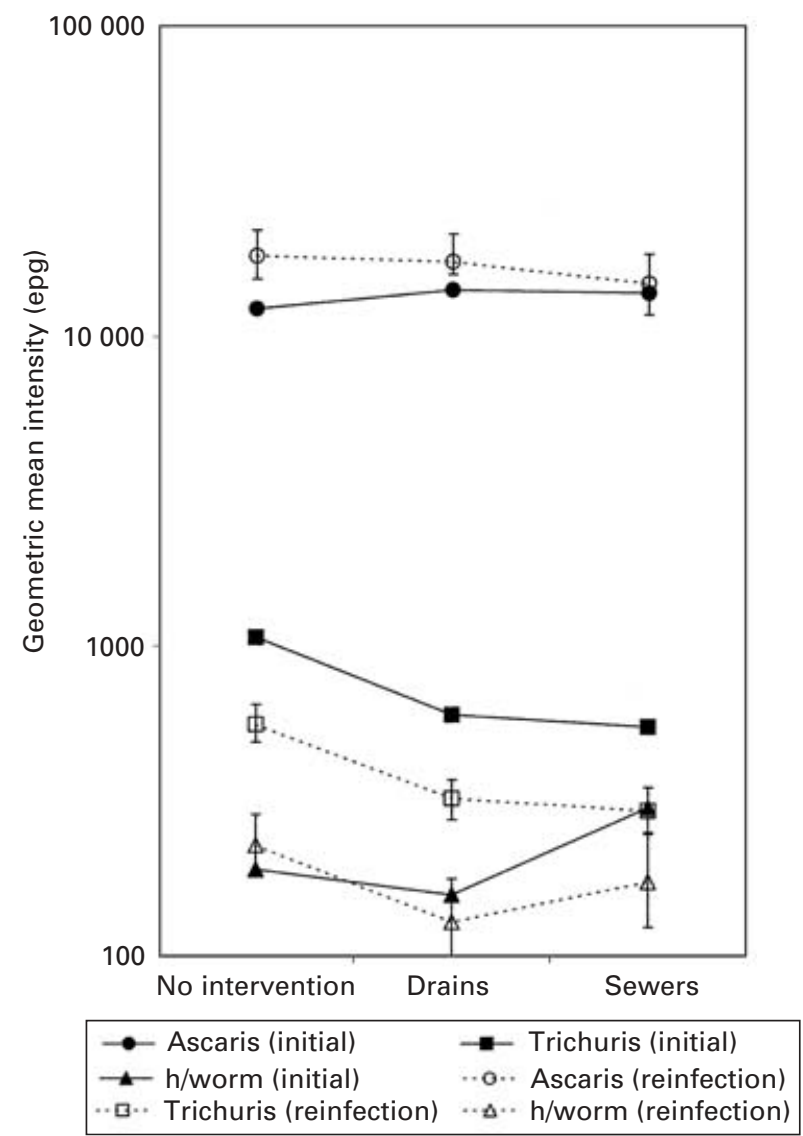

Fig. 2. Geometric mean intensities of infection in eggs per gram (epg), initially and after reinfection over 9 months, by sanitation group: Salvador, Brazil, 1989/90. Error bars show $95 \%$ confidence intervals for reinfection intensities.

the anomalously high intensity found in Group 3 before treatment was no longer apparent.

\section{Predisposition to reinfection}

In considering a child's reinfection status, 4 possible combinations exist: a child may have been infected at the first examination and at the end of the reinfection period $(++)$, at the first examination but not at the end $(+-)$, at the end but not at the first examination $(-+)$, or at neither $(--)$. Table 3 shows the numbers of children in each category, for each species.

From Table 3 it can be calculated that, for children in Group 1, the relative risk that those infected with Ascaris before treatment would again be infected 9 months later, when compared with those children who were initially uninfected, was $1.30(66.0 \% \mathrm{vs}$. $50 \cdot 8 \%$ ). In each case, this predisposition to reinfection by previously infected children is highly significant (Table 4). However, it is not constant across the study groups. For Ascaris in Groups 2 and 3 the relative risk is $2 \cdot 33$ and $2 \cdot 20$ respectively. Similar patterns can be seen for Trichuris and hookworm. For each species there is a tendency for the relative risks to be greater in Groups 2 and 3 (the groups with sanitary infrastructure) than in Group 1, the 
Table 3. Comparison of infection and reinfection rates (9 months after treatment) in children aged 5-14 years by study group: Salvador, $1989 / 90$

\begin{tabular}{|c|c|c|c|c|c|c|}
\hline & \multicolumn{2}{|c|}{$\begin{array}{l}\text { G1 } \\
\text { (No intervention) }\end{array}$} & \multicolumn{2}{|c|}{$\begin{array}{l}\text { G2 } \\
\text { (Drains only) }\end{array}$} & \multicolumn{2}{|c|}{$\begin{array}{l}\text { G3 } \\
\text { (Drains and sewers) }\end{array}$} \\
\hline & $n$ & $\%$ & $n$ & $\%$ & $n$ & $\%$ \\
\hline \multicolumn{7}{|c|}{ Ascaris } \\
\hline$--{ }^{\mathrm{a}}$ & 90 & $(49 \cdot 2)$ & 204 & $(72 \cdot 6)$ & 259 & $(75 \cdot 5)$ \\
\hline-+ & 93 & $(50 \cdot 8)$ & 77 & $(27 \cdot 6)$ & 84 & $(24 \cdot 5)$ \\
\hline+- & 129 & $(34 \cdot 0)$ & 92 & $(35 \cdot 7)$ & 96 & $(46 \cdot 2)$ \\
\hline++ & 250 & $(66 \cdot 0)$ & 166 & $(64 \cdot 3)$ & 112 & $(53 \cdot 8)$ \\
\hline \multicolumn{7}{|c|}{ Trichuris } \\
\hline-- & 30 & $(50 \cdot 0)$ & 103 & $(68 \cdot 7)$ & 133 & $(78 \cdot 7)$ \\
\hline-+ & 30 & $(50 \cdot 0)$ & 47 & $(31 \cdot 3)$ & 36 & $(21 \cdot 3)$ \\
\hline+- & 109 & $(21 \cdot 7)$ & 123 & $(31 \cdot 6)$ & 180 & $(47 \cdot 1)$ \\
\hline++ & 393 & $(78 \cdot 3)$ & 266 & $(68 \cdot 4)$ & 202 & $(52 \cdot 9)$ \\
\hline \multicolumn{7}{|c|}{ Hookworm } \\
\hline-- & 371 & $(88 \cdot 3)$ & 472 & $(96 \cdot 3)$ & 478 & $(95 \cdot 4)$ \\
\hline-+ & 49 & $(11 \cdot 7)$ & 18 & $(3 \cdot 7)$ & 23 & $(4 \cdot 6)$ \\
\hline+- & 89 & $(62 \cdot 7)$ & 23 & $(46 \cdot 9)$ & 33 & $(66 \cdot 0)$ \\
\hline++ & 53 & $(37 \cdot 3)$ & 26 & $(53 \cdot 1)$ & 17 & $(34 \cdot 0)$ \\
\hline
\end{tabular}

a -- , never infected; -+ , gained infection; +-, lost infection; ++ , reinfected.

Table 4. Strength and significance of predisposition to reinfection in children aged 5-14 years, by study group: Salvador, 1989/90

\begin{tabular}{|c|c|c|c|c|c|c|}
\hline & \multicolumn{2}{|c|}{$\begin{array}{l}\text { Group } 1 \\
\text { (No intervention) }\end{array}$} & \multicolumn{2}{|l|}{$\begin{array}{l}\text { Group } 2 \\
\text { (Drains only) }\end{array}$} & \multicolumn{2}{|c|}{$\begin{array}{l}\text { Group } 3 \\
\text { (Drains and sewers) }\end{array}$} \\
\hline & $\mathrm{RR}^{\mathrm{a}}$ & $P^{\mathrm{b}}$ & $\mathrm{RR}$ & $P$ & $\mathrm{RR}$ & $P$ \\
\hline Ascaris & $\begin{array}{l}1 \cdot 30 \\
(1 \cdot 12-1 \cdot 52)\end{array}$ & **** & $\begin{array}{l}2 \cdot 33 \\
(1 \cdot 93-2 \cdot 86)\end{array}$ & ***** & $\begin{array}{l}2 \cdot 20 \\
(1 \cdot 76-2 \cdot 75)\end{array}$ & ***** \\
\hline Trichuris & $\begin{array}{l}1 \cdot 57 \\
(1 \cdot 30-1 \cdot 89)\end{array}$ & ***** & $\begin{array}{l}2 \cdot 19 \\
(1 \cdot 79-2 \cdot 66)\end{array}$ & ****** & $\begin{array}{l}2 \cdot 48 \\
(1 \cdot 91-3 \cdot 22)\end{array}$ & ***** \\
\hline Hookworm & $\begin{array}{l}3 \cdot 19 \\
(2 \cdot 28-4 \cdot 49)\end{array}$ & ***** & $\begin{array}{l}14 \cdot 35 \\
(9 \cdot 25-22 \cdot 55)\end{array}$ & ***** & $\begin{array}{l}7 \cdot 39 \\
(4 \cdot 35-12 \cdot 62)\end{array}$ & ***** \\
\hline
\end{tabular}

a RR, Relative Risk of reinfection in previously infected children, compared to previously uninfected children (95\% confidence interval).

b Significance (Chi-squared test): *** $P<0.001$; **** $P<0.0001$.

non-intervention group. While the reinfection rates decrease slightly from Group 1 to Group 3, the new infection rates fall more sharply.

The same analysis was performed with regard to heavy infections. Again, there are 4 possible combinations: a child may have been heavily infected at the first examination and again at the end of the 9 months reinfection period $(\mathrm{HH})$, heavily infected at the first examination but not at the end (HL), heavily infected at the end but not at the first examination $(\mathrm{LH})$, or uninfected, lightly or moderately infected in both examinations (LL) (Table 5).

For the 3 nematodes studied, the predisposition to heavy infection by previously heavily infected children was highly significant in all 3 study groups
(Table 6). The relative risk of those heavily infected before treatment being again heavily infected 9 months later $(\mathrm{HH})$, when compared with those who were not heavily infected initially ( $\mathrm{LH})$, was greater in Groups 2 and 3 for Ascaris, Trichuris and hookworm than in Group 1. For all 3 species, the heavy reinfection rates were similar in the 3 study groups but the new heavy infection rates decrease from Group 1 towards Group 3 (Table 5); this determines the relative risk patterns in Table 6 .

The household size and age of children lightly and heavily reinfected in the 3 study groups were checked and found to be similar, indicating that heavy infection was not a consequence of the household size or number or age of children. 
Table 5. Comparison of heavy infection and reinfection rates (9 months after treatment) in children aged 5-14 years, by study group: Salvador, 1989/90

\begin{tabular}{|c|c|c|c|c|c|c|}
\hline & \multicolumn{2}{|c|}{$\begin{array}{l}\text { G1 } \\
\text { (No intervention) }\end{array}$} & \multicolumn{2}{|c|}{$\begin{array}{l}\text { G2 } \\
\text { (Drains only) }\end{array}$} & \multicolumn{2}{|c|}{$\begin{array}{l}\text { G3 } \\
\text { (Drains and sewers) }\end{array}$} \\
\hline & $n$ & $\%$ & $n$ & $\%$ & $n$ & $\%$ \\
\hline \multicolumn{7}{|c|}{ Ascaris } \\
\hline $\mathrm{LL}^{\mathrm{a}}$ & 431 & $(89 \cdot 4)$ & 451 & $(92 \cdot 8)$ & 480 & $(94 \cdot 7)$ \\
\hline $\mathrm{LH}$ & 51 & $(10 \cdot 6)$ & 35 & $(7 \cdot 2)$ & 27 & $(5 \cdot 3)$ \\
\hline HL & 60 & $(75 \cdot 0)$ & 38 & $(71 \cdot 7)$ & 31 & $(70 \cdot 4)$ \\
\hline $\mathrm{HH}$ & 20 & $(25 \cdot 0)$ & 15 & $(28 \cdot 3)$ & 13 & $(29 \cdot 6)$ \\
\hline \multicolumn{7}{|c|}{ Trichuris } \\
\hline $\mathrm{LL}$ & 407 & $(88 \cdot 9)$ & 423 & $(91 \cdot 8)$ & 454 & $(96 \cdot 2)$ \\
\hline $\mathrm{LH}$ & 51 & $(11 \cdot 1)$ & 38 & $(8 \cdot 2)$ & 18 & $(3 \cdot 8)$ \\
\hline HL & 70 & $(67 \cdot 3)$ & 53 & $(67 \cdot 9)$ & 49 & $(62 \cdot 0)$ \\
\hline $\mathrm{HH}$ & 34 & $(32 \cdot 7)$ & 25 & $(32 \cdot 1)$ & 30 & $(38 \cdot 0)$ \\
\hline \multicolumn{7}{|c|}{ Hookworm } \\
\hline $\mathrm{LL}$ & 520 & $(97 \cdot 2)$ & 523 & $(99 \cdot 1)$ & 533 & $(98 \cdot 7)$ \\
\hline LH & 15 & $(2 \cdot 8)$ & 5 & $(0 \cdot 9)$ & 7 & $(1 \cdot 3)$ \\
\hline HL & 21 & $(77 \cdot 8)$ & 7 & $(63 \cdot 6)$ & 9 & $(81 \cdot 8)$ \\
\hline $\mathrm{HH}$ & 6 & $(22 \cdot 2)$ & 4 & $(36 \cdot 4)$ & 2 & $(18 \cdot 2)$ \\
\hline
\end{tabular}

${ }^{a}$ LL, uninfected, light or medium infection; LH, gained heavy infection; HL, lost heavy infection; $\mathrm{HH}$, heavily reinfected.

Table 6. Strength and significance of predisposition to heavy reinfection in children aged 5-14 years, by study group: Salvador, 1989/90

\begin{tabular}{|c|c|c|c|c|c|c|}
\hline & \multicolumn{2}{|c|}{$\begin{array}{l}\text { Group } 1 \\
\text { (No intervention) }\end{array}$} & \multicolumn{2}{|l|}{$\begin{array}{l}\text { Group } 2 \\
\text { (Drains only) }\end{array}$} & \multicolumn{2}{|c|}{$\begin{array}{l}\text { Group } 3 \\
\text { (Drains and sewers) }\end{array}$} \\
\hline & $\mathrm{RR}^{\mathrm{a}}$ & $P^{\mathrm{b}}$ & $\mathrm{RR}$ & $P$ & $\mathrm{RR}$ & $P$ \\
\hline Ascaris & $\begin{array}{l}2 \cdot 36 \\
(1 \cdot 44-3 \cdot 86)\end{array}$ & **** & $\begin{array}{l}3 \cdot 93 \\
(2 \cdot 24-6 \cdot 89)\end{array}$ & ***** & $\begin{array}{l}5 \cdot 55 \\
(3 \cdot 06-10 \cdot 08)\end{array}$ & ***** \\
\hline Trichuris & $\begin{array}{l}2 \cdot 94 \\
(1 \cdot 99-4 \cdot 35)\end{array}$ & ***** & $\begin{array}{l}3 \cdot 89 \\
(2 \cdot 47-6 \cdot 12)\end{array}$ & ***** & $\begin{array}{l}9 \cdot 96 \\
(6 \cdot 29-15 \cdot 81)\end{array}$ & ***** \\
\hline Hookworm & $\begin{array}{l}7 \cdot 96 \\
(3 \cdot 33-19 \cdot 02)\end{array}$ & ***** & $\begin{array}{l}38 \cdot 40 \\
(15 \cdot 48-95 \cdot 24)\end{array}$ & ***** & $\begin{array}{l}14 \cdot 03 \\
(2 \cdot 27-71 \cdot 77)\end{array}$ & ***** \\
\hline
\end{tabular}

${ }^{a}$ RR, Relative Risk of a heavily infected child being heavily reinfected 9 months later, compared with children who were not heavily infected initially (95\% confidence interval).

b Significance (Chi-squared test): *** $P<0 \cdot 001$; **** $P<0 \cdot 0001$.

\section{Predisposition to infection with multiple species}

An interaction was apparent between infections with different species. Table 7 shows that, taking 2 species at a time, children infected with 1 species are more likely than others to be infected with the second. The relative risks are significantly greater than 1 for Ascaris vs. Trichuris, Ascaris vs. hookworm and Trichuris vs. hookworm. For each pair of species they are greater in Groups 2 and 3 than in Group 1; with the single exception of Trichuris with hookworm in Group 3, they are significantly so (Table 8).

The same pattern could be seen with respect to reinfection after treatment, and also heavy infection and reinfection as defined above (data not shown).

\section{DISCUSSION}

In a previous paper (Moraes et al. 2004), we showed how the epidemiology of 3 species of intestinal nematode in low-income areas of Salvador differs between areas with and without sanitation infrastructure. As the level of sanitation improved (passing from Group 1 to Group 2 and then to Group 3), the following trends could be noted: (i) prevalence and (for Trichuris) intensity of infection declines; (ii) risk factors for infection become more numerous and more significant, particularly for Ascaris and Trichuris.

In the present paper, we have documented the following further trends: (i) clustering of cases by 
Table 7. Interaction between infections with nematode species in children aged 5-14 years by study group before treatment: Salvador, 1989

\begin{tabular}{|c|c|c|c|c|c|c|}
\hline & \multicolumn{2}{|c|}{$\begin{array}{l}\text { G1 } \\
\text { (No intervention) }\end{array}$} & \multicolumn{2}{|c|}{$\begin{array}{l}\text { G2 } \\
\text { (Drains only) }\end{array}$} & \multicolumn{2}{|c|}{$\begin{array}{l}\text { G3 } \\
\text { (Drains and sewers) }\end{array}$} \\
\hline & $n$ & $\%$ & $n$ & $\%$ & $n$ & $\%$ \\
\hline \multicolumn{7}{|c|}{ Ascaris vs. Trichuris } \\
\hline$--^{\mathrm{a}}$ & 46 & $(21 \cdot 7)$ & 141 & $(42 \cdot 2)$ & 176 & $(45 \cdot 0)$ \\
\hline-+ & 166 & $(78 \cdot 3)$ & 193 & $(57 \cdot 8)$ & 215 & $(55 \cdot 0)$ \\
\hline+- & 31 & $(7 \cdot 4)$ & 37 & $(12 \cdot 5)$ & 24 & $(10 \cdot 0)$ \\
\hline++ & 388 & $(92 \cdot 6)$ & 260 & $(87 \cdot 5)$ & 216 & $(90 \cdot 0)$ \\
\hline \multicolumn{7}{|c|}{ Ascaris vs. Hookworm } \\
\hline-- & 173 & $(81 \cdot 6)$ & 324 & $(97 \cdot 0)$ & 371 & $(95 \cdot 1)$ \\
\hline-+ & 39 & $(18 \cdot 4)$ & 10 & $(3 \cdot 0)$ & 19 & $(4 \cdot 9)$ \\
\hline+- & 299 & $(71 \cdot 4)$ & 253 & $(85 \cdot 2)$ & 202 & $(83 \cdot 8)$ \\
\hline++ & 120 & $(28 \cdot 6)$ & 44 & $(14 \cdot 8)$ & 39 & $(16 \cdot 2)$ \\
\hline \multicolumn{7}{|c|}{ Trichuris vs. Hookworm } \\
\hline-- & 71 & $(92 \cdot 2)$ & 177 & $(99 \cdot 4)$ & 195 & $(97 \cdot 5)$ \\
\hline-+ & 6 & $(7 \cdot 8)$ & 1 & $(0 \cdot 6)$ & 5 & $(2 \cdot 5)$ \\
\hline+- & 401 & $(72 \cdot 4)$ & 400 & $(88 \cdot 3)$ & 377 & $(87 \cdot 5)$ \\
\hline++ & 153 & $(27 \cdot 6)$ & 53 & $(11 \cdot 7)$ & 54 & $(12 \cdot 5)$ \\
\hline
\end{tabular}

a -- , infected with neither; -+ , infected with the second; +- , infected with the first; ++ , infected with both.

Table 8. Strength and significance of interaction between infections with two nematode species in children aged 5-14 years by study group, before treatment: Salvador, 1989

\begin{tabular}{|c|c|c|c|c|c|c|}
\hline & \multicolumn{2}{|c|}{$\begin{array}{l}\text { Group } 1 \\
\text { (No intervention) }\end{array}$} & \multicolumn{2}{|l|}{$\begin{array}{l}\text { Group } 2 \\
\text { (Drains only) }\end{array}$} & \multicolumn{2}{|c|}{$\begin{array}{l}\text { Group } 3 \\
\text { (Drains and sewers) }\end{array}$} \\
\hline & $\mathrm{RR}^{\mathrm{a}}$ & $P^{\mathrm{b}}$ & $\mathrm{RR}$ & $P$ & $\mathrm{RR}$ & $P$ \\
\hline Ascaris with Trichuris & $\begin{array}{l}1 \cdot 18 \\
(1 \cdot 11-1 \cdot 26)\end{array}$ & ****** & $\begin{array}{l}1 \cdot 51 \\
(1 \cdot 37-1 \cdot 67)\end{array}$ & ***** & $\begin{array}{l}1 \cdot 64 \\
(1 \cdot 49-1 \cdot 81)\end{array}$ & $* * * *$ \\
\hline Ascaris with hookworm & $\begin{array}{l}1 \cdot 55 \\
(1 \cdot 13-2 \cdot 15)\end{array}$ & ** & $\begin{array}{l}4 \cdot 93 \\
(2 \cdot 70-9 \cdot 09)\end{array}$ & ***** & $\begin{array}{l}3 \cdot 31 \\
(1 \cdot 95-5 \cdot 55)\end{array}$ & ***** \\
\hline Trichuris with hookworm & $\begin{array}{l}3 \cdot 53 \\
(1 \cdot 94-6 \cdot 45)\end{array}$ & $* * *$ & $\begin{array}{l}19 \cdot 50 \\
(5 \cdot 12-74 \cdot 22)\end{array}$ & ***** & $\begin{array}{l}5 \cdot 00 \\
(2 \cdot 22-11 \cdot 30)\end{array}$ & **** \\
\hline
\end{tabular}

a RR, Relative Risk of infection with the second species in those who are infected with the first, compared with those who are not ( $95 \%$ Confidence Interval).

b Significance (Chi-squared test): $* * P<0 \cdot 01$; *** $P<0 \cdot 001$; **** $P<0 \cdot 0001$.

household becomes more marked, and hence more significant; (ii) prevalence and (in the main) intensity of reinfection decline; (iii) predisposition of individuals to reinfection and to heavy reinfection becomes more marked; (iv) interaction between infections with different species becomes stronger.

Some of these aspects, particularly predisposition, are at times considered as if they were purely biological factors. For example, when Anderson (1986) noted that predisposition is often statistically stronger in the younger age groups, he considered only immunological explanations; and Bundy et al. (1985) used a model whose parameters were based on data from a Jamaican orphanage to analyse the transmission dynamics of Trichuris in the different environment of villages in St Lucia.
However, the results presented here have shown all these aspects to vary in a consistent manner, with few exceptions, between communities whose principal difference is their level of environmental sanitation infrastructure. It is hard to avoid the conclusion that these trends are consequences of the sanitation improvements. To the extent that this is so, these phenomena cannot be entirely explained by biological factors such as variations in host susceptibility; rather, we must seek causes in the host's environment, where the parasites are transmitted.

Our study was not designed to permit analysis of the data by individual community without prejudice to the statistical significance of many of the results reported here. However, we saw no evidence that any 
of the communities was significantly different from the other two in the same exposure group with regard to the patterns of infection we describe.

\section{Household clustering}

Clustering of intestinal helminth infections by household is a well-known phenomenon, although less common in hookworm (Killewo et al. 1991; Behnke et al. 2000). Indeed Cort, Schapiro \& Stoll (1929) concluded from their classic studies that the family, and not the individual, should be considered the unit of infection. What is new in the present study is the finding that the degree of clustering by household depends on environmental conditions.

There are two ways in which the environmental transmission of intestinal helminths could produce a pattern of infection clustered by household. First, a substantial amount of transmission could be occurring within the domestic domain of the household, from one member to another (Cairncross et al. 1996). Second, if the characteristics of some households are such as to expose them heavily to infection from other households (for example, in a household living beside an open sewer), then cases of infection are likely to be clustered in such households in a nonrandom way. Indeed, for Ascaris and Trichuris, though not for hookworm, we found more significant household risk factors in the groups with infrastructure than the control (Moraes et al. 2004).

Whichever phenomenon is the cause of the household clustering (whether intra- or interhousehold transmission is primarily responsible), its variation between study groups leads to the same conclusion; the component of transmission which has been prevented by sanitation is less affected by the characteristics of the household than the component which remains.

\section{Prevalence and intensity of reinfection}

The decline in overall prevalence and intensity of reinfection from Group 1 to Group 3 confirms our previous finding (Moraes et al. 2004) that the sanitation measures had succeeded in controlling transmission, or at least an important component of it. It does not always follow that use of toilets will reduce transmission of intestinal helminths (Gross et al. 1989; Asaolu et al. 2002), but community sanitation infrastructure may have more impact, by preventing contamination of the public environment with worm eggs, than the facilities enjoyed by individual households (Schulz \& Kroeger, 1992).

\section{Predisposition to reinfection}

We found that children initially infected with an intestinal helminth species were more likely than others to be reinfected after treatment. Predisposition to reinfection has been reported after one chemotherapeutic intervention for Ascaris (Thein-Hlaing, ThanSaw \& Myint-Lwin, 1987; Forrester et al. 1990), Trichuris (Haswell-Elkins, Elkins \& Anderson, 1987; Bundy et al. 1987) and hookworm (Behnke et al. 2000; Quinnell et al. 2001).

To some extent, apparent predisposition to reinfection could arise from imperfect efficacy of cure. Some children would appear to have been reinfected, when in reality they had remained infected throughout because the drug failed to eliminate all their parasites. However, the predisposition was strongest for hookworm, for which the treatment was most efficacious. Moreover, this cannot explain the varying strength of this predisposition across the study groups; as noted above, no significant differences in efficacy of cure were found between the 3 study groups.

We also found that this predisposition was stronger in the study groups with sanitary infrastructure. As with household clustering, this can be explained to some extent by the increased importance of household risk factors in those study groups; children in the households which are more exposed to infection are more likely to be infected and also to be reinfected.

The strength of predisposition to heavy infections also increased across the study groups. Predisposition to heavy infection with Ascaris, Trichuris and hookworm has been demonstrated in various countries (Behnke et al. 2000; Bundy et al. 1987; Forrester et al. 1990). Some studies (Forrester et al. 1990; Chan, Bundy \& Kan, 1994a) have documented such predisposition at the family level. The factors responsible for predisposition to heavy infection may be related to susceptibility or exposure. Some studies have suggested that predisposition is affected more by environmental factors than genetic ones (Bundy \& Cooper, 1988; Chan, Bundy \& Kan, 1994b), and geneticists admit that genetic effects explain less than half the variance in human worm burden (Quinnell, 2003). Others have suggested behavioural factors, in the context of a faecally contaminated environment (Haswell-Elkins et al. 1988).

Such predisposition has been shown here to be dependent to a certain extent on environmental conditions; to that extent, it is not related to susceptibility. The higher degree of predisposition to reinfection encountered in the communities with improved sanitation must therefore be explained largely in terms of the environmental conditions of the individual and the household, whether these refer to (i) environmental hygiene in general, or (ii) the degree to which the household environment has remained contaminated with worm eggs or larvae excreted before the first round of chemotherapy. In either case, it is suggestive of transmission in the domestic, rather than the public domain (Cairncross et al. 1996). 


\section{Interaction between species}

Of course, the second explanation above cannot account for the association found between infections with different species of helminth in the same children. Not all of those who have looked for such an association have found it (Croll \& Ghadirian, 1981; Kroeger et al. 1992), suggesting that it is at least variable between different settings. Whether or not there is a biological factor which could account for it, the tendency for the interaction to be stronger in the neighbourhoods with better sanitation facilities suggests an environmental explanation; that the environment and behaviour of certain households, in certain neighbourhoods, renders them far more exposed to faecal contamination than others, and hence more exposed to infection with various species of geohelminth.

\section{Conclusions and implications}

The evidence from a number of aspects of the epidemiology of 3 different species of parasite all points in the same direction. That is, that where sanitation is lacking, a significant part of transmission occurs in ways which are not affected by characteristics of individual households, and therefore out of their control. It is reasonable to presume that this transmission occurs outside the household, somewhere in the public domain.

This component would appear to be largely controlled by sanitation improvements, leaving a residual degree of transmission which does depend on household risk factors, and presumably occurs within the domestic domain, the household environment and the areas immediately adjoining it.

While public domain transmission is clearly beyond the control of individual households, so also may some forms of transmission in the domestic domain; for instance, proximity to overflowing or visible sewage or rubbish. The significance of risk factors such as these is an indication that the health impact of the environmental sanitation could have been greater if the system had been properly maintained.

Nevertheless, the finding that domestic factors assume greater importance when transmission in the public domain is controlled implies that environmental sanitation creates conditions for other inputs, aimed at such domestic factors, to produce synergistic effects.

Dr Moraes' work was supported by the Brazilian National Research Council, CNPq, and the Fundação Escola Politécnica da Bahia; the field work costs were supported by the International Development Research Centre of Canada. The mebendazole was donated by the Bahia State Secretariat for Health. We are grateful to Simon Brooker for his comments on a draft of this paper. Our special gratitude goes to the children, families and Residents' Associations of the neighbourhoods studied, who gave the field work their full cooperation. We recognize the important contribution of Jacira Cancio to the management of the field work. The hard work and dedication of the field workers Ana Maria (in memory), Ana Paula, Andréa, Arivaldo, Celeste, Cida, Cristina, Edilene, Helena, Raquel, Rosilene, Selma, Susana, Thais and Valdete were vital to the success of the project. From the UFBA/Laboratory of Parasitology Dr Neuza M. Alcântara gave full supervision to the laboratory activities. Antônia, Cássia, Clara, Hyldete, Luziane, Paulo and Tereza played an important role in the stool examination.

\section{REFERENCES}

Anderson, R. M. (1986). The population dynamics and epidemiology of intestinal nematode infections. Transactions of the Royal Society of Tropical Medicine and Hygiene 80, 686-696.

ANDERSON, R. M. \& MEDLEY, G. F. (1985). Community control of helminth infections of man by mass and selective chemotherapy. Parasitology 90, 629-660.

ASAOLU, S. O., OFOEZIE, I. E., ODAMUYIWA, P. A., SOWEMIMO, O. A. \& OGUNNIYI, T. A. (2002). Effect of water supply and sanitation on the prevalence and intensity of Ascaris lumbricoides infection among pre-school-age children in Ajebandele and Ifewara, Ogun State, Nigeria. Transactions of the Royal Society of Tropical Medicine and Hygiene 96, 600-604.

BEHNKE, J. M., DE ClERCQ, D., SACKO, M., GILBERT, F. S., ouattara, D. B. \& Vercruysse, J. (2000). The epidemiology of human hookworm infections in the southern region of Mali. Tropical Medicine and International Health 5, 343-354.

Bundy, D. A. P., Chan, M. S. \& GUYATT, H. L. (1995). The practicality and sustainability of vaccination as an approach to parasite control. Parasitology 110 (Suppl.), S51-S58.

BUNDY, D. A. P., COOPER, E. S., THOMPSON, D. E., DIDIER, J. M., Anderson, R. M. \& SIMMONs, I. (1987). Predisposition to Trichuris trichiura infections in humans. Epidemiology and Infection 98, 65-71.

BUNDY, D. A. P., THOMPSON, D. E., COOPER, E. S., GOLDEN, M. H. \& ANDERSON, R. M. (1985). Population dynamics and chemotherapeutic control of Trichuris trichiura infection of children in Jamaica and St. Lucia. Transactions of the Royal Society of Tropical Medicine and Hygiene 79, 759-764.

BUNDY, D. A. P. \& COOPER, E. S. (1988). The evidence of predisposition to trichuriasis in humans: comparison of institutional and community studies. Annals of Tropical Medicine and Parasitology 82, 251-256.

Cairncross, S., Blumenthal, U., KOlsky, P., Moraes, L. \& TAYEH, A. (1996). The public and domestic domains in the transmission of disease. Tropical Medicine and International Health 1, 27-34.

CHAN, L., BUNDY, D. A. P. \& KAN, S. P. (1994a). Aggregation and predisposition to Ascaris lumbricoides and Trichuris trichiura at the familial level. Transactions of the Royal Society of Tropical Medicine and Hygiene 88, 46-48.

CHAN, L., BUNDY, D. A. P. \& KAN, S. P. (1994b). Genetic relatedness as a determinant of predisposition in Ascaris lumbricoides and Trichuris trichiura infection.

Parasitology 108, 77-80. 
CORT, W. W., SCHAPIRO, L. \& STOLL, N. R. (1929). A study of reinfection after treatment with hookworm and Ascaris in two villages in Panama. American Fournal of Hygiene 10, 614-625.

CROLL, N. A. \& GHADIRIAN, E. (1981). Wormy persons: contributions to the nature and patterns of overdispersion with Ascaris lumbricoides, Ancylostoma duodenale, Necator americanus and Trichuris trichiura. Tropical and Geographic Medicine 33, 241-248.

FARIA, J. A. S. (1972). Prevalência de helmintos em escolares de 7-14 anos na cidade do Salvador. Revista da Sociedade Brasileira de Medicina Tropical 6, 261-264.

FORRESTER, J.E., SCOTT, M.E., BUNDY, D. A. P. \& GOLDEN, M. H. N. (1988). Clustering of Ascaris lumbricoides and Trichuris trichiura infections within households. Transactions of the Royal Society of Tropical Medicine and Hygiene 82, 282-288.

FORRESTER, J.E., SCOTT, M. E., BUNDY, D. A. P. \& GOLDEN, M. H. N. (1990). Predisposition of individuals and families in Mexico to heavy infection with Ascaris lumbricoides and Trichuris trichiura. Transactions of the Royal Society of Tropical Medicine and Hygiene 84, 272-276.

GROSS, R., SCHELL, B., BISI MOLINA, M. C., LEÃO, M. A. C. \& STRACK, U. (1989). The impact of improvement of water supply and sanitation facilities on diarrhoea and intestinal parasites: a Brazilian experience with children in two low-income urban communities. Revista de Saúde pública, São Paulo 23, 214-220.

HASWELL-ELKINS, M. R., ELKINS, D. B. \& ANDERSON, R. M.

(1987). Evidence for predisposition in humans to infection with Ascaris, hookworm, Enterobius and Trichuris in a South Indian fishing community. Parasitology 95, 323-337.

HASWELL-ELKINS, M. R., ELKINS, D. B., MANJULA, K., MiCHAEL, E. \& ANDERSON, R. M. (1988). An investigation of hookworm infection and reinfection following mass anthelminthic treatment in the south Indian fishing community of Vairavnkuppam. Parasitology 96, $565-577$.
KILlewo, J. Z. J., CAIRNCRoss, S., SMET, J. E. M., MAIKWANO, L. F. \& VAn asten, H. (1991). Patterns of hookworm and Ascaris infection in Dar es Salaam. Acta Tropica 48, 247-249.

KLOETZEL, K. (1990). Reinfection after treatment of schistosomiasis : environment or "predisposition"? Revista do Instituto Médico de São Paulo 32, 138-146.

KROEgER, A., SCHUlZ, S., WITTE, B., SKEWES-RAMm, R. \& ETZleR, A. (1992). Helminthiasis and cultural change in the Peruvian rainforest. Fournal of Tropical Medicine and Hygiene 95, 104-113.

MORAES, L. R. S., CANCIO, J. A., CAIRNCROSS, S. \& HUTTLY, S. (2003). Impact of drainage and sewerage on diarrhoea in poor urban areas in Salvador, Brazil. Transactions of the Royal Society of Tropical Medicine and Hygiene 97, 153-158.

MORAES, L. R. S., CANCIO, J. A. \& CAIRNCROSS, S. (2004). Impact of drainage and sewerage on intestinal nematode infections in poor urban areas in Salvador, Brazil. Transactions of the Royal Society of Tropical Medicine and Hygiene 98, 197-204.

QUINNELL, R. J. (2003). Genetics of susceptibility to human helminth infection. International Fournal for Parasitology 33, 1219-1231.

QUINNELL, R. J., GRIFFIN, J., NOWELL, M. A., RAIKo, A. \& PRITChard, D. (2001). Predisposition to hookworm infection in Papua New Guinea. Transactions of the Royal Society of Tropical Medicine and Hygiene $\mathbf{9 5}$, 139-142.

SChulz, S. \& KROEgER, A. (1992). Soil contamination with Ascaris lumbricoides eggs as an indicator of environmental hygiene in urban areas of north-east Brazil. Fournal of Tropical Medicine and Hygiene 95, 95-103.

THEIN-HLAING, THAN-SAW \& MYINT-LWIN (1987).

Reinfection of people with Ascaris lumbricoides following single, 6-month and 12-month interval mass chemotherapy in Okpo village, rural Burma. Transactions of the Royal Society of Tropical Medicine and Hygiene 81, 140-146. 